\title{
Recent bloom of filamentous algae in Lake Baikal is caused by Spirogyra Link., 1820 of local origin
}

\author{
Elena Mincheva*1, Tatiana Peretolchina ${ }^{1}$, Tatyana Triboy ${ }^{1}$, Yrij Bukin ${ }^{1}$, Luybov \\ Kravtsova $^{1}$, Andrey Fedotov ${ }^{1}$, and Dmitry Sherbakov ${ }^{1,2}$ \\ ${ }^{1}$ Limnological institute SB RAS, Ulan-Batorskaya 3, 664033 Irkutsk, Russia; \\ ${ }^{2}$ Irkutsk State University, Sukhe-Bator 5, 664003 Irkutsk, Russia \\ * Author for correspondence: Elena Mincheva \\ e-mail: elenakuznetsova01@gmail.com
}

\begin{abstract}
Molecular phylogeny inferred from $r b c \mathrm{~L}$ nucleotide sequences obtained from the single sterile filaments of green algae collected around the perimeter of Lake Baikal indicates the polyphyletic origin of the representatives of genus Spirogyra Link., 1820 inhabiting the lake. The common ancestor of all Baikal Spirogyra dates back at least to 20 MYA. This roughly coincides with the age of continuously existing freshwater body in the confines of current Baikal. The descendants of this node include both Baikal and non-Baikal species and thus suggesting a complex history of multiple emigrations and immigrations. There is at least one major lineage of the Baikal Spirogyra in the phylogeny descending uninterruptedly from the common ancestor of all Spirogyra species found so far in the lake. The likely explanation is its permanent presence in the ecosystem. All this allows us to hypothesize that the current bloom is a spectacular but natural response of the Baikal ecosystem to the increased pollution.
\end{abstract}

Keywords: Lake Baikal, Spirogyra, Algal bloom, anthropogenic pollution, ancient Lake

\section{Introduction}

High production of filamentous algae is among the most obvious and dramatic manifestations of unwanted changes in different kinds of aquatic ecosystems [1-3]. It may take place both in marine and freshwater environments often in response to an elevated influx of nutrients or other impacts promoting production [4]. Although the cases of economic exploitation of filamentous algae are known [5], usually their mass occurrence in an ecosystem is regarded as the indicator of ecological damage going on [6-9]. Recently the usual temporal and spatial patterns of green algal growth were spoiled dramatically in Lake Baikal (East Siberia) [10-14]. Since Lake Baikal is the most ancient and the largest of giant freshwater lakes [15] containing ca. 20\% of the world's fresh water and home for highly diverse and endemic biota, this development has caused strong public and scientific concern. However, the very scale of Lake Baikal and the diversity of its biotopes offer an additional challenge to the study of its ecosystem changes. Indeed, different regions of the lake range from highly polluted spots permanently suffering under strong human impact to pristine areas where no ecological changes 
still may be detected $[11,12]$. Therefore the results obtained for one locality are hardly expandable to the other parts of the same lake. Previous studies had demonstrated that several of filamentous algal species belonging to genus Spirogyra comprise large if not a major part of the algal blooms in the polluted parts of Lake Baikal [13]. Several species of Spirogyra were found in shallow bays of Lake Baikal as rare filaments [16]. This makes it possible to hypothesize, that the blooming Spirogyra could originate from those few surviving opportunists exploiting an increased influx of nutrients. The alternative hypothesis proposes that the blooms were caused by exotic invaders using the window of opportunity existing due to anthropogenic impact. We believe that the expected further development of ecological transformations of the Baikal ecosystem depends on which hypothesis is true with a much more catastrophic perspective in the latter case.

Since the first studies revealed that the algal community of the green sludge consists of many different filamentous algae, we have adopted the approach based on the identification of single filaments. Therefore in order to elucidate the evolutionary roots of Spirogyra we have isolated individual algal filaments from 18 localities scattered along the shore of the lake. The barcode chloroplast gene $r b c \mathrm{~L}$ was used to provide phylogenetic evidence for Baikal origin of the most abundant species of Spirogyra and to demonstrate the existence of complicated immigration/emigration patterns of its relation with non-Baikal habitats.

\section{Materials and methods}

Samples of filamentous Charophyta were collected by divers at the 18 localities along the perimeter of Lake Baikal during the three expeditions of RV "Titov" from 2016 to 2019 (Fig.1, Table S1). 


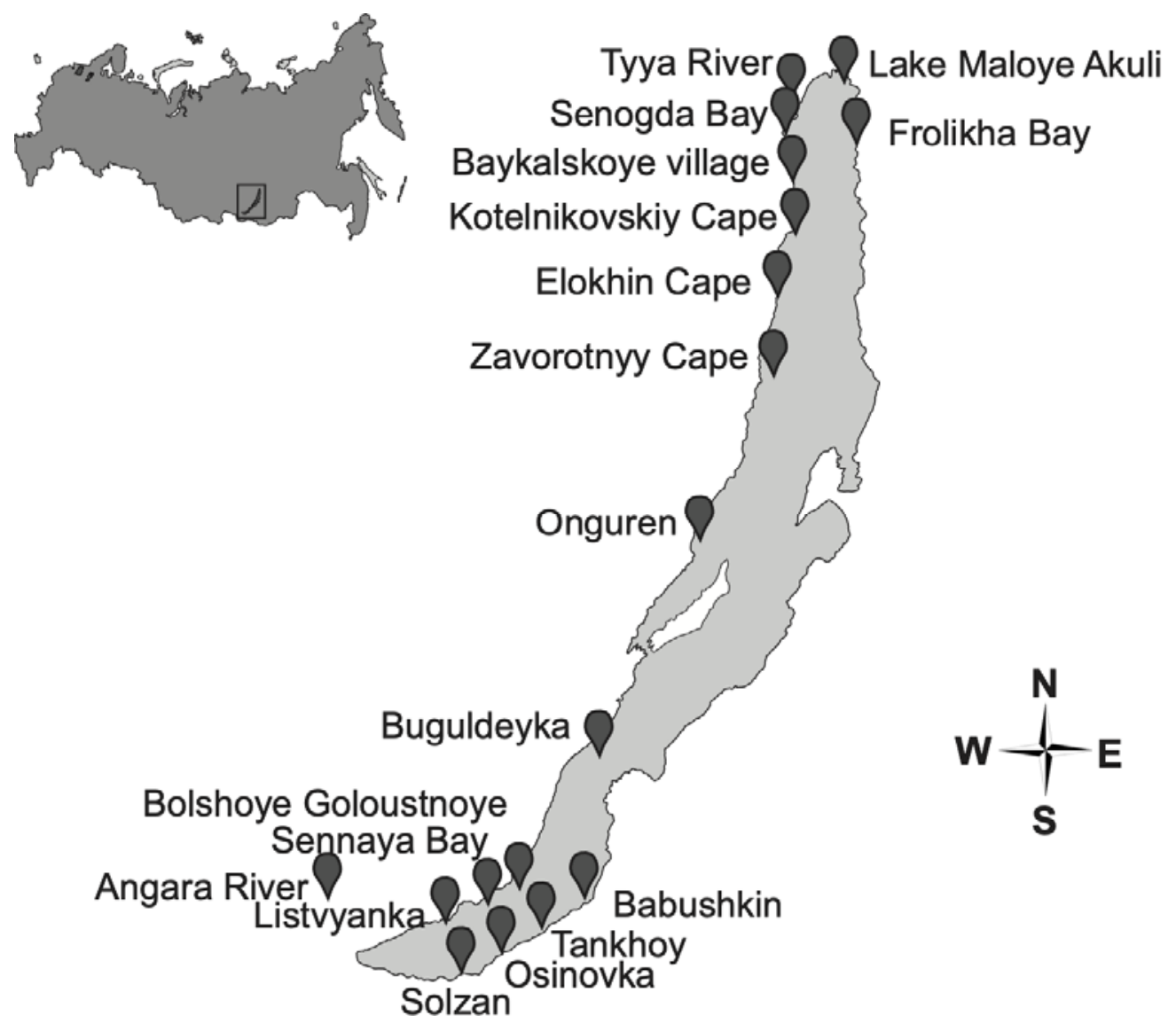

Fig. 1. Map of localities where filamentous green algae were sampled

Separate sterile (no conjugation) filaments of Spirogyra were manually picked up under a microscope and placed in tubes with $2 \%$ CTAB and frozen at $-20^{\circ} \mathrm{C}$.

DNA was extracted according to the modified protocol by Doyle and Dickson [17].

Fragments of $r b c \mathrm{~L}$ were amplified using primers rbcL183 M28F 5'GGTGTTGGATTTAAAGCTGGTGT-3' and $r b c \mathrm{~L}$ M1390R 5'CTTTCAAAYTTCACAAGCAGCAG-3' [18]. 35 cycles were preceded with 4 min. long pre-denaturation at $95^{\circ} \mathrm{C}$ and were $20 \mathrm{sec}$. at $95^{\circ} \mathrm{C}, 20 \mathrm{sec}$. min at $55^{\circ} \mathrm{C}$, $1.5 \mathrm{~min} 72^{\circ} \mathrm{C}$ (5 min at the last cycle). For the second stage, we have developed the Spirogyra-specific primers Spir_rbcL_1340R 5'-CTAACTCAGGACTCCATTTG-3', Spir_rbcL_330F 5'- CTATTGTAGGTAACGTATTTGG-3', which were used with the same protocol as at stage 1 . These primers flank the most variable part of $r b c \mathrm{~L}$ about $1 \mathrm{kB}$ long. PCR amplification of the respective fragments was performed with the Biolabmix (Novosibirsk, Russia) HS180Taq kit in $25 \mu \mathrm{l}$ of the reaction mixture in a Bio-Rad (USA) thermocycler Bio-Rad T100. After electrophoresis purification and extraction with the gel elution kit (Biosilica Co., Novosibirsk, Russia) the direct sequencing of forward and reverse sequences were performed in Research and Production Company SYNTOL (Russia) using an ABI 3130 automated sequencer. 


\section{Phylogenetic inferences.}

DNA sequences of $r b c \mathrm{~L}$ obtained in this study (Table 1 in Supplemantary), were merged together with the sequences of Spirogyra available in NCBI database [19-21], the alignment was checked with mafft [22, 23]. Three species of other Charales (Zygogonium ericetorium, Zygnema cylindricum, and Mougeoutia sp.) were used as the outgroup rooting the phylogeny. The phylogenetic inferences were performed with IQ-TREE [24] with optimal model of molecular evolution (TIM3+I+G4) chosen according to its BIC value, the robustness of the topology was tested both using ultra-fast bootstrap [25] and SH-alrt test [26].

BEAST ver.1.8.4 [27] was used for Bayesian estimations of the ages of nodes numbered on Fig.2a. The ML-tree inferred with IQ-TREE was used as the user-tree, as well as the TIM3+I+G4 model chosen by IQ-TREE was assumed $a$ priori. The logarithmically relaxed model of the molecular clock [28] was used together with the evolutionary birth-death model [29]. As the source of calibration, the monophyletic clades of Hawaiian Spirogyra restricted to single islands were used under the assumption of approximately simultaneous appearance of the island and expansion of Spirogyra to its water bodies [30]. Similar dating strategy was successfully used in [31, 32].

The same tree was used for studies of evolutionary parameters of the distribution of the Spirogyra unique haplotypes Mesquite v.3.6 [33].

\section{Phylogeographic analysis}

The phylogeographic analysis was based on all sequence data available on Spirogyra by the fall of 2019. Unfortunately, the sampling localities are known for less than a half of $r b c \mathrm{~L}$ sequences published. Therefore we have approximated the geographic distribution by a binary trait "Baikal" vs. "non-Baikal" and used both parsimony and likelihood approaches to describe the present and past trends in the evolution of this trait.

The amount of long-term isolation between Baikal and not Baikal haplotypes on an evolutionary time-scale was estimated by permutation test on the tree topology inferred from nucleotide sequences [33]. The tree was subjected to 150 random branch-and-bounds, after which different metrics of the amount of phylogenetic signals such as retention index or the parsimonious number of steps. This procedure was repeated for $10^{6}$ times to compromise between the vast size of tree space and the probability of repeated samplings.

\section{Results and discussion}

The main focus of the study was at the origin of the mass haplotypes present in Lake Baikal: are they the recent invaders having their roots outside the lake, or they are the endemic opportunists originating from previously rare species found there in the middle of XX century [16].

Phylogenetic inference performed for $366 r b c \mathrm{~L}$ sequences (157 unique haplotypes) resulted in a fully resolved tree with highly supported most if internal nodes (Fig.2). 

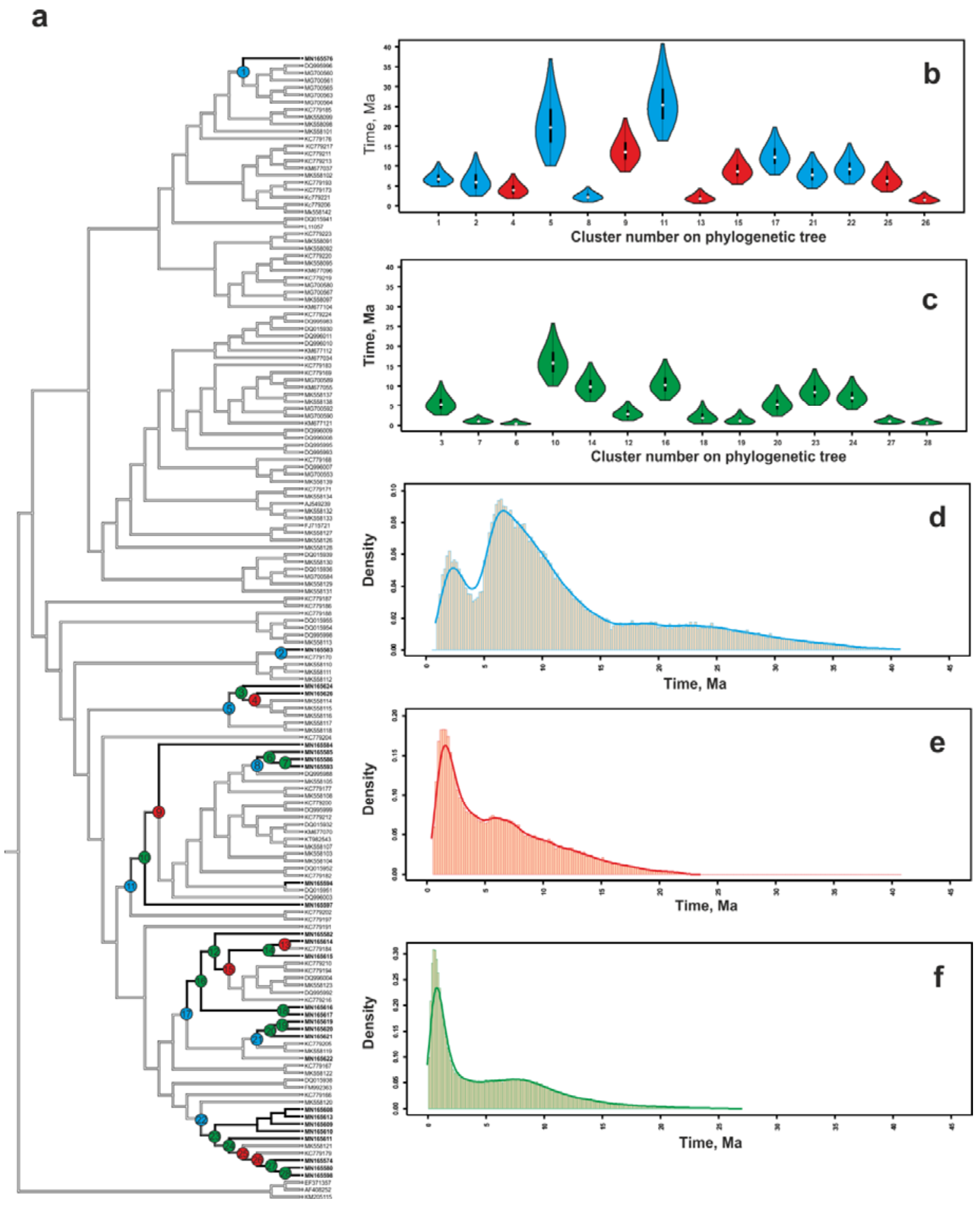

Fig. 2. Evolution of the distribution of Spirogyra between Lake Baikal and other water bodies. A. Ultrametric BEAST tree estimated from the maximum likelihood tree inferred from $r b c \mathrm{~L}$ sequences (Table S1 and Fig.S1). The blue square outlines the major lineage containing all but one haplotypes of the Baikal samples. Numbered circles denote tree nodes for which time estimates have been performed. Blue circles indicate immigration events, red circles indicate emigrations, and the green ones indicate nodes with all descendants remaining in Baikal. B. and C. Time estimates for the nodes outlined at panel A. Violin plots cover 95\% 
confidence limits. D, E, and F: Probability distributions for D) no migration nodes, E) emigration from Baikal; F) immigration into Baikal

The most important feature of the tree is that it splits into two major lineages, one of which contains the deep node ancestral to all Baikal sequences but a single one. The descendants of this node contain both Baikal OTUs and OTUs of American, Japanese, Hawaiian and European origin.

Up to date, Spirogyra diversity is studied in four localities: California [19], Hawaii [20], Japan [21] and Lake Baikal (current study). Other sequences clustering within the genus and presented in the NCBI database were treated as being of unknown origin. The ML phylogeny inferred (Fig. S1) suggests that each of the regions was populated by Spirogyra species more than once. All possible directions of past migration were found except for the direct migration between Lake Baikal and Hawaii.

Likelihood ratio test for the hypothesis of asymmetry vs. symmetry of transition between "Baikal" - "non-Baikal" treated as a binary character gives 6.98454086. Assuming $\chi^{2} \mathrm{df}=1$, this favors the «asymmetric» hypothesis with rejection level at $p=0.0082$. It was found, that the exchange with the outside world was biased (bias $\approx 0.13833$ ) towards immigration to Lake Baikal. Never the less, emigration must be significant since none of the two unidirectional models cannot explain the current distribution of Spyrogira if the phylogeny is accepted. Note that due to the high dispersal potential [34] the distribution of Spyrogira species is likely to be at equilibrium at any time. However, only one haplotype was found both in Lake Baikal and other fresh water bodies. This indicates noticeable difficulties in long-term successful immigration to Lake Baikal of the new Spirogyra. This finding contradicts strongly the common opinion of recent invasion to Lake Baikal by some exotic representatives of Charophyta.

The results of permutation test (Fig. S2) suggest a significantly high amount of phylogeny signal, making the change of state in the distribution character less probable than speciation.

The Bayesian approach and based on geological dating of the appearance times of Hawaiian Islands allowed to estimate the most likely substitution rate for the $r b c \mathrm{~L}$ to $0.011 \%$ for million years with $95 \%$ confidence limits from $0.0063 \%$ to $0.016 \%$ per million years. The common ancestor of "Baikal" sequences dates back approximately to 18MYA which approaches ca. 20-25MYA which are regarded as the age of large freshwater lake permanently existing in confines of the current lake [15]. After that, approximately the first half of the history of the lake was dominated by the immigration of different lineages of Spirogyra followed by a long period of both emigrations and immigrations. Interestingly, the period preceding the cooling down of climate was very favorable for Spirogyra judging by the increase of the intralacustrine divergence (Fig. 2f) followed by a decrease in Pleistocene. This corroborates with the data by Izhboldina and coauthors [16, 35] who found the representatives of this genus as very rare single filaments in shallow waters of Lake Baikal in the middle of XX century. Thus the recent blooms appear to be a reverse of the long trend. 
The results reported here indicate that it is likely that 1) multiple Spirogyra species were present in confines of current Lake Baikal since the appearance of a large fresh continuously existing water body ca. 25MYA. 2)There were multiple immigrations and emigrations from the outside, but establishing permanent lineages inside the lake was relatively rare making the Baikal algae noticeably isolated; 3)The Spirogyra species blooming recently in Lake Baikal are most likely local opportunists rather than successful exots exploiting an increase in nutrient influxes. We believe that taking into account long persistence and high variation in numbers over a short period of time, our findings presented here, allow us to propose, that the blooms of filamentous green algae may at least partially explain why relatively long "diatomless" periods in the well-studied diatom record of paleo-climate of Lake Baikal [36, 37] did not leave noticeable traces in evolutionary histories of Baikal benthic animals [38, 39].

\section{Funding}

This work was supported by the governmentally funded projects No. 03452019-0004 and 0345-2019-0006.0

\section{References}

1. Horner RR,Welch E (1981) Stream periphyton development in relation to current velocity and nutrients. Canadian Journal of Fisheries and Aquatic Sciences 38(4):449-457. (https://doi.org/10.1139/f81-062)

2. Chetelat J, Pick F, Morin A, Hamilton P (1999) Periphyton biomass and community composition in rivers of different nutrient status. Canadian Journal of Fisheries and Aquatic Sciences 56(4):560-569.

3. Biggs BJ (2000) Eutrophication of streams and rivers: dissolved nutrientchlorophyll relationships for benthic algae. Journal of the North American Benthological Society 19(1):17-31.

4. Larned ST (2010) A prospectus for periphyton: recent and future ecological research. Journal of the North American Benthological Society 29(1):182-206. (https://doi.org/10.1899/08-063.1)

5. Georgianna DR, Mayfield SP (2012) Exploiting diversity and synthetic biology for the production of algal biofuels. Nature 488(7411):329. (https://doi.org/10.1038/nature11479)

6. Guo L (2007) Doing battle with the green monster of Taihu Lake. Science 317(5842):1166-1166. (https://doi.org/10.1126/science.317.5842.1166)

7. Sun S, et al. (2008) Emerging challenges: Massive green algae blooms in the Yellow Sea. (Nature Publishing Group). (https://doi.org/10.1038/npre.2008.2266.1)

8. Ye Nh, et al. (2011) «Green tides» are overwhelming the coastline of our blue planet: taking the world's largest example. Ecological Research 26(3):477. (https://doi.org/10.1007/s11284-011-0821-8)

9. Smetacek V, Zingone A (2013) Green and golden seaweed tides on the rise. Nature 504(7478):84. (https://doi.org/10.1038/nature12860) 
10. Kravtsova L, et al. (2012) Disturbances of the vertical zoning of green algae in the coastal part of the Listvennichnyi gulf of Lake Baikal. Doklady Biological Sciences 447(1):350. (https://doi.org/10.1134/s0012496612060026)

11. Kravtsova LS, et al. (2014) Nearshore benthic blooms of filamentous green algae in Lake Baikal. Journal of Great Lakes Research 40:441-448. (https://doi.org/10.1016/j.jglr.2014.02.019)

12. Timoshkin O, et al. (2016) Rapid ecological change in the coastal zone of Lake Baikal (East Siberia): Is the site of the world's greatest freshwater biodiversity in danger? Journal of Great Lakes Research 42(3):487-497. (https://doi.org/10.1016/j.jglr.2016.02.011)

13. Romanova E, Kravtsova L, Izhboldina L, Khanaev I, Sherbakov DY (2015) Identification of filamentous green algae from an area of local biogenic pollution of Lake Baikal (Listvennichnyi bay) using SSU18S rDNA. Russian Journal of Genetics: Applied Research 5(2):118-125. (https://doi.org/10.17816/ecogen11423-33)

14. Kobanova GI, Takhteev VV, Rusanovskaya OO, Timofeyev MA (2016) Lake Baikal ecosystem faces the threat of eutrophication. International Journal of Ecology 2016. (https://doi.org/10.1155/2016/6058082)

15. Mats V, Shcherbakov D, Efimova I (2011) Late cretaceous-cenozoic history of the Lake Baikal depression and formation of its unique biodiversity. Stratigraphy and Geological Correlation 19(4):404-423.

16. Izhboldina L (1990) Meio-and macrophytobenthos of Lake Baikal (algae). (Publ. Irkutsk University, Irkutsk, Russia.).

17. Doyle JJ, Dickson EE (1987) Preservation of plant samples for DNA restriction endonuclease analysis. Taxon 36(4): 715-722 (https://doi.org/10.2307/1221122)

18. McManus HA, Lewis LA (2011) Molecular phylogenetic relationships in the freshwater family Hydrodictyaceae (Sphaeropleales, Chlorophyceae), with an emphasis on Pediastrum duplex. Journal of Phycology 47(1):152-163. (https://doi.org/10.1111/j.1529-8817.2010.00940.x)

19. Stancheva R, Hall JD, McCourt RM, Sheath RG (2013) Identity and phylogenetic placement of Spirogyra species (Zygnematophyceae, Charophyta) from california streams and elsewhere. Journal of phycology 49(3):588-607. (https://doi.org/10.1111/jpy.12070)

20. Chen C, Barfuss MH, Pröschold T, Schagerl M (2012) Hidden genetic diversity in the green alga Spirogyra (Zygnematophyceae, Streptophyta). BMC evolutionary biology 12(1):77. (https://doi.org/10.1186/1471-2148-12-77)

21. Takano T, Higuchi S, Ikegaya H, Matsuzaki R, Kawachi M, Takahashi F, \& Nozaki H. (2019) Identification of 13 Spirogyra species (Zygnemataceae) by traits of sexual reproduction induced under laboratory culture conditions. Scientific reports 9(1):7458. (https://doi.org/10.1038/s41598-019-43454-6)

22. Katoh K, Standley DM (2013) Mafft multiple sequence alignment software version 7: improvements in performance and usability. Molecular biology and evolution 30(4):772-780. (https://doi.org/10.1093/molbev/mst010) 
23. Katoh K, Kuma Ki, Toh H, Miyata T (2005) Mafft version 5: improvement in accuracy of multiple sequence alignment. Nucleic acids research 33(2):511-518. (https://doi.org/10.1093/nar/gki198)

24. Nguyen LT, Schmidt HA, von Haeseler A, Minh BQ (2014) IQ-TREE: a fast and effective stochastic algorithm for estimating maximum-likelihood phylogenies. Molecular biology and evolution 32(1):268-274. (https://doi.org/10.1093/molbev/msu300)

25. Minh BQ, Nguyen MAT, von Haeseler A (2013) Ultrafast approximation for phylogenetic bootstrap. Molecular biology and evolution 30(5):1188-1195. (https://doi.org/10.1093/molbev/mst024)

26. Anisimova M, Gascuel O (2006) Approximate likelihood-ratio test for branches: a fast, accurate, and powerful alternative. Systematic Biology 55(4):539_ 552. (https://doi.org/10.1080/10635150600755453)

27. Drummond AJ, Rambaut A (2007) Beast: Bayesian evolutionary analysis by sampling trees. BMC evolutionary biology 7(1):214.

28. Drummond AJ, Ho SY, Phillips MJ, Rambaut A (2006) Relaxed phylogenetics and dating with confidence. PLoS biology 4(5):e88. (https://doi.org/10.1371/journal.pbio.0040088)

29. Gernhard T (2008) The conditioned reconstructed process. Journal of theoretical biology 253(4):769-778. (https://doi.org/10.1016/j.jtbi.2008.04.005)

30. Price JP, Clague DA (2002) How old is the Hawaiian biota? Geology and phylogeny suggest recent divergence. Proceedings of the Royal Society of London. Series B: Biological Sciences 269(1508):2429-2435. (https://doi.org/10.1098/rspb.2002.2175)

31. Givnish TJ, et al. (2008) Origin, adaptive radiation and diversification of the Hawaiian lobeliads (Asterales: Campanulaceae). Proceedings of the Royal Society B: Biological Sciences 276(1656):407-416. (https://doi.org/10.1098/rspb.2008.1204)

32. Haines WP, Schmitz P, Rubinoff D (2014) Ancient diversification of hyposmocoma moths in Hawaii. Nature communications 5:3502. (https://doi.org/10.1038/ncomms4502)

33. Maddison WP (2008) Mesquite: a modular system for evolutionary analysis. Evolution 62:1103-1118.

34.Wang JC, Hoshaw RW, McCourt RM (1989) Diversity of Spirogyra (Chlorophyta) filament types on an altitudinal gradient. British Phycological Journal 24(4):367-373. (https://doi.org/10.1080/00071618900650381)

35. Izhboldina L (2007) Atlas i opredelitel vodorosley bentosa i periphitona ozera baikal (meio- i makrophity): s kratkimi ocherkami po ikh ekologii (atlas and manual for determination of benthic and periphytic algae of Lake Baikal (meio-and macrophytes) with short information about their ecology), Timoshkin O., Genkal S.

36. Grachev MA, Vorobyova SS, Likhoshway YV, Goldberg EL, Ziborova GA, Levina OV, \& Khlystov OM. (1998) A high-resolution diatom record of the palaeoclimates of East Siberia for the last 2.5My from Lake Baikal. Quaternary 
Science Reviews 17(12):1101-1106. (https://doi.org/10.1016/s02773791(98)00048-1)

37. Williams DF (1997) Lake Baikal record of continental climate response to orbital insolation during the past 5 million years. Science 278(5340):1114-1117. (https://doi.org/10.1126/science.278.5340.1114)

38. Sherbakov DY (1999) Molecular phylogenetic studies on the origin of biodiversity in Lake Baikal. Trends in ecology \& evolution 14(3):92-95. (https://doi.org/10.1016/s0169-5347(98)01543-2)

39. Fazalova V, Nevado B, Peretolchina T, Petunina J, Sherbakov D (2010) When environmental changes do not cause geographic separation of fauna: differential responses of Baikalian invertebrates. BMC evolutionary biology 10(1):320. (https://doi.org/10.1186/1471-2148-10-320) 